\title{
Structural Variation In Gill Vasculature Among Some Batiod Elasmobranchs Examined Using Corrosion Casting And SEM
}

\author{
R.L. Sherman ${ }^{1 *}$, A. Lametschwandtner ${ }^{2}$, and R.E. Spieler ${ }^{3,4}$
}

${ }^{1}$ Nova Southeastern University, Division of Math, Science, and Technology, 3301 College Avenue, Fort Lauderdale, Florida, USA, 33314

${ }^{2}$ Department of Organismic Biology, University of Salzburg, Salzburg, Hellbrunnerstr. 34, A-5020, Salzburg, Austria

${ }^{3}$ Nova Southeastern University Oceanographic Center; ${ }^{4}$ Guy Harvey Research Institute, 8000 North Ocean Drive, Dania Beach, Florida, USA, 33004

\section{shermanr@nova.edu}

Comparison of basic functional morphological structures among related species can provide an understanding of taxonomic and ecological relationships. Classic studies of gill vasculature indicate the gross anatomy of elasmobranch gills is similar in most species, and in general, resembles those of teleosts. However, studies of fine gill structure examining arterio-arterial pathways in several species of batoid elasmobranchs (Order: Rajiiformes, Suborder: Myliobatoidei) reported some structural differences [1]. These differences include the presence, in urolophids (Urobatis jamaicensis, U. mucosus, U. paucimaculatus), of 1) a tip channel, possibly an extension of the afferent filament artery that runs along the top of the filament corpus cavernosum, and 2) a vascular arcade, a vessel which connects the afferent filament arteries of a hemibranch near the tip of each filament (Fig. 1) [1,2]. These structures, once believed to be unique to urolophids appear to be recent adaptations as changes in these structure can be traced through suborders from more primitive to more derived. Animals of mixed species and sexes were collected, perfused, and acrylic casts made of the circulatory system. The resulting casts were examined and photographed by SEM. In this ongoing series of studies the yellow ray (U. jamaicensis), cownose ray (Rhinoptera bonasus), southern stingray (Dasyatis americana), atlantic stingray (D. sabina), freshwater stingray (Potamotrygon motoro) (Suborder: Myliobatoidea), little skate, winter skate, thorny skate (Raja erinacea, $R$. ocellata, and $R$. radiata) (Suborder: Rajoidea), and the deep sea electric ray (Benthobatis marcida) (Suborder: Torpedinoidea) have been examined.

In the myliobatids the tip channel and vascular arcade are distinct vascular structures (Fig. 1). However, in the rajids the vascular arcade is more sinus-like and the tip channel appears to be embedded in the body of the corpus cavernosum (Fig. 2,3,). In Benthobatis, however, this structure appears to be non-existent (Fig. 4). These results indicate not only are the tip channel and vascular arcade not identical across suborders, the tip channel and vascular arcade as identifiable structures are not present in the more primitive fishes. Additional research is required to determine the phylogenetic and physiologic significance of these structures.

\section{References}

[1] J. Donald 1989. Vascular anatomy of the gills of the Stingarees Urolophus mucosus and $U$. paucimaculatus (Urolophidae, Elasmobranchii). J. of Morph. 200:37-46. 
[2] R.L. Sherman and R.E. Spieler 1998. Examination of gill vasculature of the yellow stingray, Urolophus jamaicensis (Urolophidae), by SEM observations of resin casts. Ital. J. Zool. 65, Suppl,:431-434.

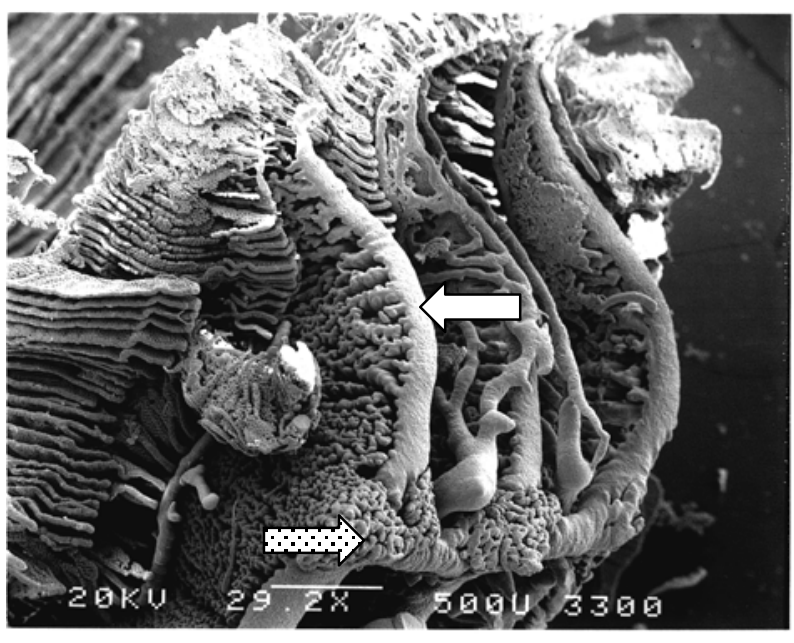

Fig. 1. Micrograph of the tip channel (white arrow) and vascular arcade (stippled arrow) from U. jamaicensis.

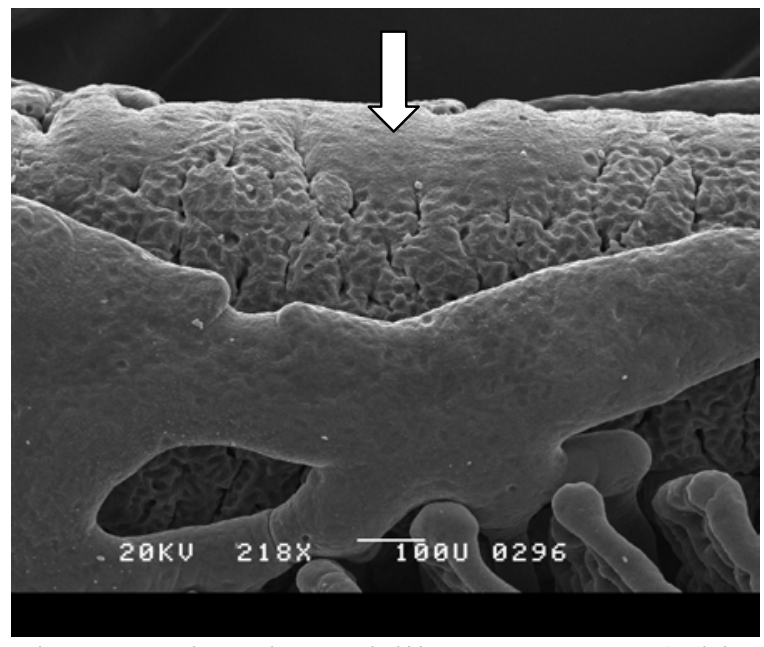

Fig. 3. Tip channel-like structure (white arrow) embedded in the corpus cavernosum of $R$. erinacea.

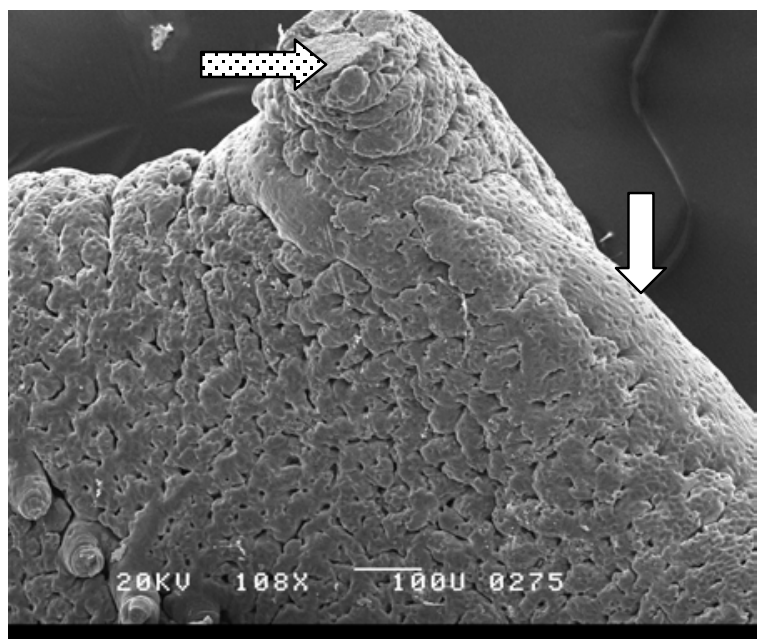

Fig. 2. Tip channel (white arrow) and a vascular arcade-like structure (stippled arrow) in $R$. ocellata.

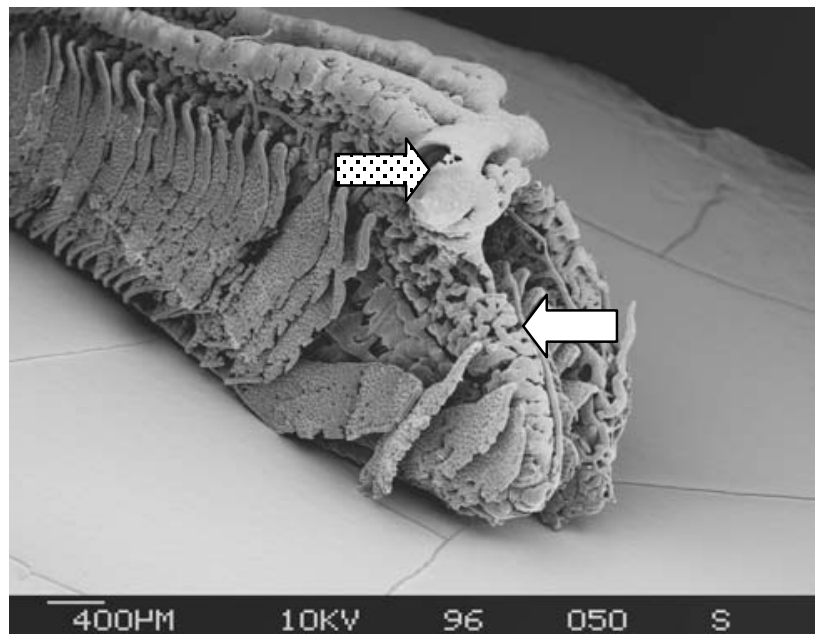

Fig. 4. Sinus like vascular arcade (stippled arrow) and absent tip channel (white arrow) in B. marcida. 